\title{
Prevalence and genetic diversity of Rhodococcus equi in wild boars (Sus scrofa), roe deer (Capreolus capreolus) and red deer (Cervus elaphus) in Poland
}

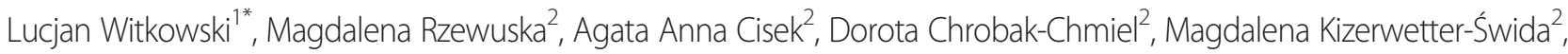
Michał Czopowicz ${ }^{1}$, Mirosław Welz ${ }^{3}$ and Jerzy Kita ${ }^{1}$

\begin{abstract}
Background: Rhodococcus equi is now considered an emerging zoonotic pathogen. Sources and routes of human infection remain unclear but foodborne transmission seems to be the most probable way. Strains of pig or bovine type are most often isolated from human cases and moreover $R$. equi is present in submaxillary lymph nodes of apparently healthy pigs and wild boars intended for human consumption. The aim of this study was to estimate the prevalence of $R$. equi in submaxillary lymph nodes in wild boars, roe deer and red deer.

Results: Samples were collected from 936 animals and 27 R. equi strains were isolated, from $5.1 \%$ of wild boars (23/452), $0.7 \%$ of red deer (2/272) and $0.9 \%$ of roe deer (2/212). Genetic diversity of all 27 isolates was studied using Vspl-PFGE method, resulting in the detection of 25 PFGE patterns and four PFGE clusters. PFGE patterns of the isolates were compared with virulence plasmid types and no concordance was observed.

Conclusions: $R$. equi was present in wild animal tissues and consumption of the game may be a potential source of $R$. equi infection for humans. To the authors' best knowledge, this is the first epidemiological report of $R$. equi prevalence in tissues of roe deer and red deer. However, risk associated with wild ruminant consumption seems marginal. Investigation of $R$. equi transmission between animals and humans based exclusively on types of virulence plasmids seems to be insufficient to identify sources of $R$. equi infection for people.
\end{abstract}

Keywords: Rhodococcosis, Epidemiology, PFGE, Wildlife, Wild ruminant

\section{Background}

Rhodococcus equi is a Gram-positive bacterium present in the intestinal microflora of grazing farm animals and wild animals such as deer, wild boars and others, as well as widespread in their environment [1-5]. Rhodococcus equi can cause diseases in various animals. However, only foals up to six months of age have a unique susceptibility to clinical disease and it is a major concern to the equine breeding industry [6]. Clinical form of this disease known as rhodococcosis mostly manifesting itself with abscesses or lymphadenitis has been also reported occasionally in other farm animals. In pigs $R$. equi causes lymphadenitis $[7,8]$ but it is also present in lymph nodes

\footnotetext{
*Correspondence: lucjan_witkowski@sggw.pl

'Laboratory of Veterinary Epidemiology and Economics, Faculty of Veterinary Medicine, Warsaw University of Life Sciences, Nowoursynowska159c, 02-776 Warsaw, Poland

Full list of author information is available at the end of the article
}

of healthy animals intended for human consumption [3, 9-13]. In ruminants the disease has been described quite rarely and most often in goats [14]. In cattle $R$. equi was isolated from purulent lesions in various tissues [10, 15-17]. Clinical cases of pyogranulomatous skin disease and pneumonia associated with $R$. equi have been rarely observed in cats and dogs [18].

The first report of R. equi isolation from tissues of wildlife was published in 2008 [19]. The presence of $R$. equi was demonstrated in $12.4 \%$ of the submaxillary lymph node samples collected from wild boars' carcasses. Afterwards, $R$. equi was isolated from $6.6 \%$ mesenteric and submaxillary lymph nodes with lymphadenitis in wild boars in Brazil, but the bacteria were not detected in lymph nodes without lymphadenitis $[12,13]$. Then, very high $R$. equi prevalence of $52 \%$ was noticed in submaxillary lymph nodes of wild boars in Japan [20]. Recently, $R$. 
equi isolation from lymphatic tissues has also been described in Poland [21]. Furthermore, the case of bronchopneumonia in wild boars caused by $R$. equi was reported in 2013 in Brazil [22].

Little is known about the occurrence of $R$. equi in wild ruminants. $R$. equi were isolated from feces of deer in New Zealand [1] and African indigenous ruminants [2]. The first isolation of $R$. equi from tissues of healthy roe deer and red deer was reported in 2014 [21]. Infection in wild ruminants associated with $R$. equi, has been thus far described only in American bison (Bison bison) with paratuberculosis where this bacterium was isolated from caseous necrotic lesions together with Mycobacterium avium subsp. paratuberculosis [23].

An increasing number of $R$. equi infections in humans have been reported in last decades and $R$. equi is now considered an emerging zoonotic pathogen [24, 25]. Even though sources and routes of human infection remain unclear, a foodborne transmission seems to be the most probable way especially by contact and consumption of raw and undercooked meat [24-26].

The virulence of $R$. equi is determined by the virulence associated proteins (Vaps). The equine $R$. equi isolates carry the vapA gene encoding virulence-associated 15-17$\mathrm{kDa}$ protein (VapA), swine and cattle isolates harbor mainly the $v a p B$ gene of the virulence-associated $20-\mathrm{kDa}$ protein (VapB), and cattle isolates can carry the vapN gene [27]. These genes are placed on virulence-associated plasmids (VAPs), VAPA, VAPB, and VAPN, respectively. The "TRAVAP" typing scheme classifies $R$. equi isolates into 4 categories: $\operatorname{tra} A^{+} / A^{+} B^{-}$"horse-type", $\operatorname{tra} A^{+} / A^{-} B^{+}$"pigtype", $\operatorname{tra}^{+} / A B^{-}$"bovine-type" and $\operatorname{tra} A^{-} / A B^{-}$plasmidless type. Avirulent strains showing no evidence of plasmids are widespread mainly in soil. From clinical cases of infections in humans, the strains of pig or bovine type have been isolated more often than avirulent or equine strains $[4,26,27]$. Analysis of restriction enzyme digestion patterns revealed several distinct VAPA types and over 20 types of VAPB $[4,12]$. Furthermore, there is a geographical diversity among human and animal isolates e.g. VAPB type 5 is predominant in Europe [21], type 8 in South America [12], type 1 and 2 in Asia [3, 20].

The aim of this study was to estimate the prevalence of $R$. equi in wild boars, roe deer and red deer carcasses intended for human consumption in Poland and to determine the genetic diversity of the isolates.

\section{Results}

A total number of 936 lymph nodes samples were evaluated; 452 from wild boars, 272 from red deer and 212 from roe deer. The animals were hunted in various regions, in 12 of 16 voivodships of Poland. In collected lymph nodes from wild boars the purulent lesions were observed in $8.4 \%$ (CI 95: 6.2-11.3 \%) of samples. Size of abscesses varied from 1 to $50 \mathrm{~mm}$ in diameter. No lesions were observed in any samples from wild ruminants. $R$. equi was isolated from lymph nodes collected from 23 wild boars (5.1; CI 95: 3.4, $7.5 \%$ ), 2 red deer (0.7; CI 95: $0.2,2.6 \%$ ) and 2 roe deer (0.9; CI 95: 0.2, $3.6 \%$ ). All $27 R$. equi isolates were recovered from tissues without any anatomopathological lesions.

Phenotypic characterization, virulence genotypes and plasmid profile of these isolates was published previously [21] and allowed to compare these features with PFGE results. All 27 isolates were subjected to genotyping with PFGE. The isolates were typeable with VspI-PFGE, resulting in the detection of 25 PFGE patterns and four PFGE clusters (A, B, C, D) (Fig. 1). The isolates were considered to be closely related above $80 \%$ of homology and assigned to the same PFGE cluster. The major cluster (A) was shared by 11 isolates from wild boars, cluster $B$ was shared by three isolates from wild boars and clusters $\mathrm{C}$ and $\mathrm{D}$ consisted of two isolates each from wild boars. The remaining 12 isolates exhibited different pulsed-field patterns. Unfortunately, the data about animals were not available in all cases and it did not allow identification of each sample with place of origin. In PFGE cluster A nine isolates harbored plasmid type 5, one type 7 and one type 11 . In cluster B two isolates contained plasmid type 5 and one isolate was plasmidless. Interestingly, two strains in cluster A and two in D isolated from wild boars were indistinguishable and had the same PFGE pattern. Both indistinguishable isolates in cluster A carried type 5 plasmid and were recovered from animals captured in the same forest. Interestingly, one strain in cluster D carried plasmid type 5 but the second was avirulent. Unfortunately, in this case origin of the strain was unknown.

\section{Discussion}

Our results confirmed occurrence of $R$. equi in submaxillary lymph nodes of apparently healthy wild boars. The prevalence of $5.1 \%$ in the studied wild boar population in Poland appears low compared to the prevalence of $12.4 \%$ in Hungary [19], and much lower than the prevalence of $52 \%$ in Japan [20]. Interestingly, the results are similar to data from Brazil (6.6\%) [13]. However, comparison of the results needs to be done with caution. In the Brazilian study $R$. equi was isolated only from wild boar lymph nodes with lymphadenitis and all investigated lymph nodes without lesions were negative. Moreover, contrary to Poland, wild boars in Brazil are not wildlife but animals exotic for local fauna, kept on commercial farms in semi-extensive conditions. Clinical cases of pulmonary infection caused by $R$. equi were described in wild boars only in Brazil [22].

In this investigation purulent lesions in lymph nodes were found in $8.4 \%$ of samples, but they were not associated 


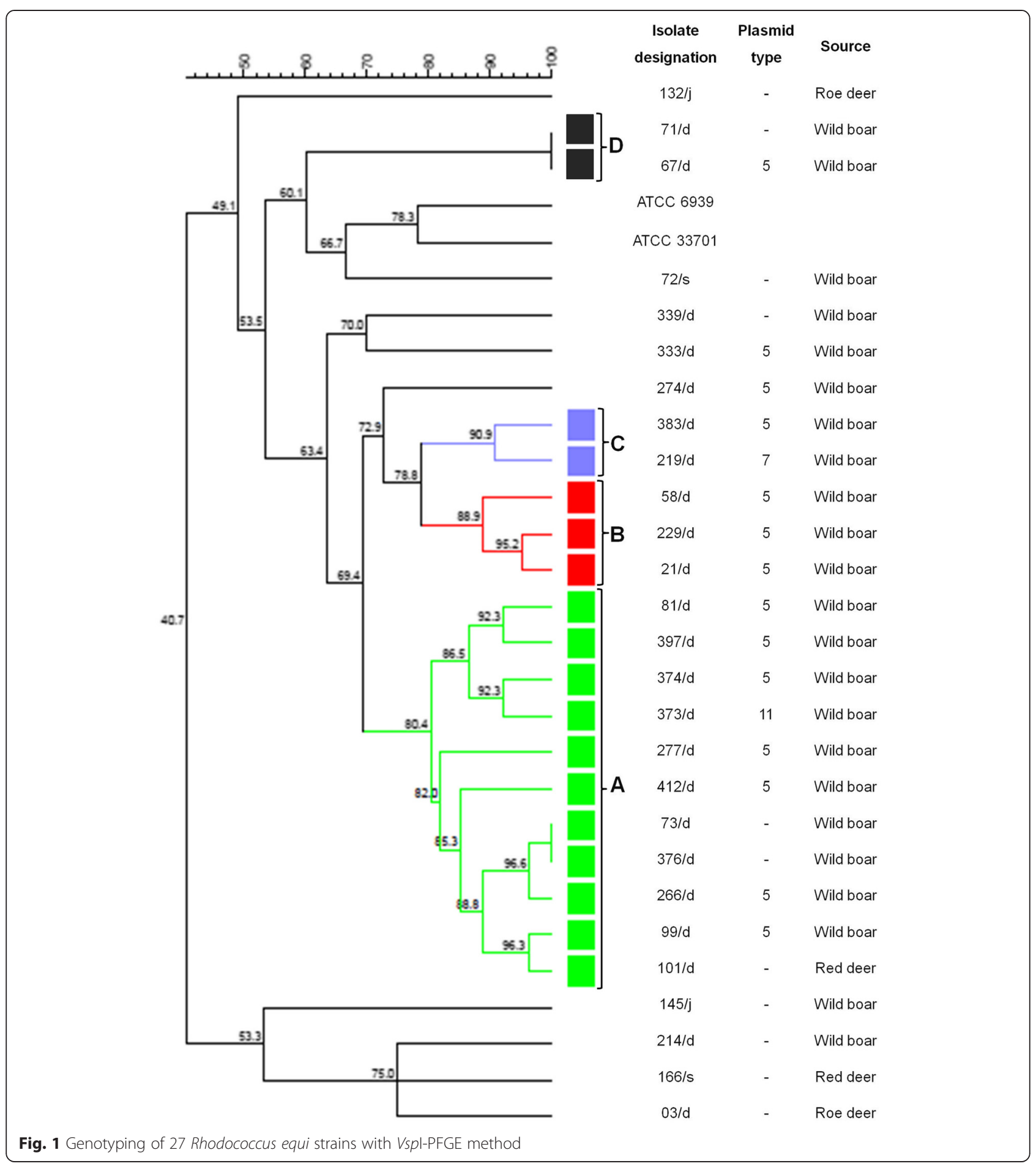

with $R$. equi infection. In comparison, in slaughtered farm pigs granulomatous lesions in the submaxillary lymph nodes caused by various pathogens were observed in $0.75 \%$ of animals [7]. Given that pigs are usually kept in buildings, feed with commercial feed, and treated with antibiotics, risk of bacterial infection is lower compared to wild animals in the natural environment.

Regarding that the methodology of $R$. equi isolation was similar in all the aforementioned studies it is interesting why $R$. equi prevalence among wild boars from different 
countries varied so much. Relatively wide differences in the prevalence of $R$. equi between studies were also observed in pigs intended for human consumption where it varied from 0.0 to $21.7 \%$ [3, 9-13]. It was found that $R$. equi prevalence in young wild boars could be higher than in older ones [20], also the prevalence in younger cattle was higher than in older cows [15]. It may suggest that older animals are more resistant to $R$. equi infection or there are other not known predisposing factors like e.g. immunocompetence of individual animal. Study from Japan showed that the prevalence of $R$. equi in wild boars was the same in various regions [20] but factors like wide dissemination of $R$. equi in the environment, density of animal population, their diet, individual susceptibility to the infection and other may have played a role.

To date, the prevalence of $R$. equi in tissues of roe deer and red deer has not been investigated. This bacterium was detected previously only in feces of deer in New Zealand [1] and other wild ruminants in Africa [2]. The R. equi isolation from tissues was also reported in $5.7 \%$ of American bison with paratuberculosis [23]. Recently, $R$. equi isolation from submaxillary lymph nodes of healthy roe deer and red deer has been described in Poland [21] and in this study the epidemiological data on this material are presented. Very low prevalence of avirulent, environmental strains of $R$. equi (less than one per cent in red deer and roe deer), and lack of tissue lesions suggest that it should be interpreted as an accidental carriage of the pathogen. Generally, ruminants seem to be relatively resistant to $R$. equi infection. In population of slaughtered cattle the prevalence of $R$. equi was very low $(0.008 \%)$ [15]. However, clinical disease has been reported sporadically in domestic goats [14] and cattle, but all descriptions of $R$. equi isolation from cattle concern animals with purulent lesions or suspected of Mycobacterium spp. infection [10, 15-17]. $R$. equi was detected alone or together with Mycobacterium spp. in granulomas in $3.9 \%$ of bovine lymph node samples in Ireland [15], $4 \%$ in Algeria [16] and $19.5 \%$ in Czech Republic [10]. These isolates were obtained mainly from retropharyngeal, bronchial and mediastinal lymph nodes which are most common sites of tuberculosis lesions. It was also suggested that Mycobacterium spp. infection could predispose to R. equi infection [23]. Purulent lesions in wildlife associated with infections with other Gram-positive bacteria including Mycobacterium spp. or Trueperella (Arcanobacterium) pyogenes $[23,28,29]$ are more frequently described. However, $R$. equi as a common soil organism of unknown clinical importance is rarely taken into consideration as a potential pathogen. Presented results suggest that infection or coinfection with $R$. equi should be more often considered as a differential diagnosis of purulent lesions in wildlife.

Genotypic method often used in the epidemiological investigations of genetic relationships between $R$. equi isolates was PFGE, however, results were inconclusive [5, 11, 17, 30-34]. In the case of $R$. equi infection in horses it was shown that many various strains were widespread in horse population but individual farms tended to harbor a particular single strain [30-32]. However, another study revealed high genetic variability not only among isolates from various countries but also on farms [33]. Furthermore, using other technique (repetitive sequence-based PCR) it was shown that one foal could be infected with multiple $R$. equi strains [34]. Application of PFGE in the investigation of swine $R$. equi strains showed high genetic diversity of strains not only between farms but also between individual animals on one farm [11]. It was suggested that infection was not presumably transmitted among animals in the herd but the environment could have been a source of infection. Interestingly, in other study cattle strains isolated from various farms had the same restriction pattern [17]. Unfortunately, in our study complete information about the origin of each positive animal was not available. Comparison of PFGE patterns and plasmid type in this study confirmed previous observation in pigs [11], horses [32] and cattle [5] where $R$. equi isolates containing the same plasmid type revealed different PFGE patterns and vice versa isolates with identical PFGE patterns contained different virulence plasmids or were plasmid-less.

$R$. equi is a zoonotic pathogen. Even though sources and routes of infection in humans remain unclear, exposure to animals or their environment may play a role in some cases of infection in humans [24-26]. $R$. equi is thought to be acquired by inhalation from soil, inoculation into wound or mucous membranes, or ingestion and passage through the alimentary tract. These results confirmed the presence of $R$. equi in tissues of wild animals intended for human consumption. It could be a source of human infection. This study showed that $R$. equi strains sharing the same plasmid type had different PFGE patterns. Thus, investigation of $R$. equi transmission between animals and humans based exclusively on types of virulence plasmids seems to be insufficient to identify sources of $R$. equi infection for people. For this purpose total genomic DNA comparison of $R$. equi strains obtained from clinical cases of infection in humans with isolates from wildlife, farm animals and environment is warranted.

\section{Conclusions}

$R$. equi was present in wild animal tissues and consumption of the game may be a potential source of $R$. equi infection for humans. To the authors' best knowledge, this is the first epidemiological report of $R$. equi prevalence in tissues of roe deer and red deer. However, risk associated with wild ruminant consumption seems marginal. 
Investigation of $R$. equi transmission between animals and humans based exclusively on types of virulence plasmids seems to be insufficient to identify sources of $R$. equi infection for people.

\section{Materials and Methods}

The study was approved by the 3rd Local Commission for Ethics in Animal Experiments (Decision No. 44/2009). Population of studied wild animals was estimated based on the data of the Polish Hunting Association monitoring in the 2009/2010 season [35]. The population of wild boars, roe deer and red deer counted 250 000, 757000 and 145000 individuals, respectively. During this season 197000 wild boars, 162000 roe deer and 41100 red deer were hunted. Required sample size (n) was determined for each animal species according to the following formula: $\mathrm{n}=\left[1.96^{2} \times \mathrm{P}_{\exp } \times\left(1-\mathrm{P}_{\exp }\right)\right] / \mathrm{d}^{2}$ assuming desired absolute precision $(\mathrm{d})$ of $5 \%$ in wild boars, and $10 \%$ in roe and red deer, expected prevalence $\left(\mathrm{P}_{\text {exp }}\right)$ of $50 \%$ and $95 \%$ level of confidence [36]. The calculations were performed using Win Episcope 2.0. Minimum sample size was 385 and 97 animals for wild boars and deer, respectively. $95 \%$ confidence intervals were calculated using Wilson score method.

According to the Polish regulation all carcasses of hunted animals are collected by a few companies. Submaxillary lymph nodes were obtained from wild boars, red deer and roe deer carcasses collected in facilities belonging to 2 companies during seasons 2009/2010 and 2010/2011. All studied samples were obtained from carcasses accepted for human consumption and stored in $-20{ }^{\circ} \mathrm{C}$ for further investigation. Refrozen lymph nodes were cut into small pieces using sterile scissors. Then, one gram of tissue was added to $3 \mathrm{ml}$ of sterile $0.9 \%$ saline and was homogenized using PRO200 homogenizer Multi-Gen 7 (PRO Scientific Inc., USA). Finally, $100 \mu \mathrm{l}$ of homogenized tissue was cultured to selective medium. $R$. equi isolation, phenotypic and genotypic identification of isolates was conducted as described previously [21]. Briefly, for the bacteria isolation modified CAZ-NB medium was used, biochemical properties were determined in API Coryne test (bioMerieux, France) and the presence of "equi factor" was studied in CAMP test. Isolate identification was confirmed by MALDI-TOF MS using VITEK MS (bioMerieux, France). The presence of four $R$. equi genes, choE, traA, vapA and $v a p B$ was determined by PCR.

PFGE was performed as previously described [31] with minor modifications. Briefly, the overnight $R$. equi cultures in BHI medium (bioMérieux, France) enriched with $0.4 \%$ glucose, $1 \%$ glycerol and $0.2 \%$ Tween 85 were adjusted to $\mathrm{OD}_{600} 0.65$ and the cells were incorporated into $1.5 \%$ (w/v) agarose discs (SeaKem Gold, Lonza, Switzerland). After $18 \mathrm{~h}$ of lysis with lysozyme $(20 \mathrm{mg} / \mathrm{ml}$, SIGMA, Germany) and RNase (50 $\mu \mathrm{g} / \mathrm{ml}$, Fermentas, Lithuania) at $37{ }^{\circ} \mathrm{C}$, discs were incubated with proteinase $\mathrm{K}(300 \mu \mathrm{g} / \mathrm{ml}$,
A\&A Biotechnology, Poland) overnight at $50{ }^{\circ} \mathrm{C}$. Then DNA in agarose discs was digested with $V s p \mathrm{I}(10 \mathrm{U} / \mu \mathrm{l}$; Fermentas, Lithuania) overnight at $37{ }^{\circ} \mathrm{C}$. The restriction fragments were separated by clamped homogenous electric field electrophoresis with a CHEF-DR II System (Bio-Rad Laboratories, USA) in a $1.1 \%(\mathrm{w} / \mathrm{v})$ agarose gel using the following conditions: running time $22 \mathrm{~h}$, temperature $14{ }^{\circ} \mathrm{C}$; voltage gradient $200 \mathrm{~V}$; included angle $120^{\circ}$. During the first run $(7 \mathrm{~h})$, an initial pulse time of $6 \mathrm{~s}$ and a final pulse time of $15 \mathrm{~s}$ were used, and during the second run $(15 \mathrm{~h})$, an initial pulse time of $23 \mathrm{~s}$ and a final pulse time of $40 \mathrm{~s}$ were used. Lambda ladder PFGE Marker (BioLabs, New England) was selected for molecular size estimation. The gel was stained with ethidium bromide $(0.5 \mu \mathrm{g} / \mathrm{ml})$ for $30 \mathrm{~min}$ at room temperature with gentle shaking, then destained in distilled water for $30 \mathrm{~min}$, documented and analysed by a VersaDoc Imaging System (model 1000) and a Quantity One software (version 4.4.0) (BioRad, USA). Afterwards, the gel images were analyzed by Gel Compar II version 4.6 (Applied Maths, Belgium) and a cluster analysis was performed by UPGMA using dice similarity coefficient with optimization set at $1 \%$ and position tolerance at $1.5 \%$. The isolates were clustered using an $80 \%$ homology cut-off, above which the isolates were considered to be closely related and assigned to the same PFGE cluster [37]. The reference $R$. equi strains ATCC 6939 and ATCC 33701 were used in the study as a control.

\section{Competing interests}

The authors declare that they have no competing interests.

\section{Authors' contributions}

LW acquisition of funding, conceiving, designing and coordination of the study, general supervision of the research group, participation in material and data collection, participation in laboratory analysis, drafting the manuscript. MR participation in acquisition of funding, participation in conceiving and designing the study, participation in laboratory analysis and assistance in drafting the manuscript. AAC participation in laboratory analysis and assistance in drafting the manuscript. DCC participation in laboratory analysis and assistance in drafting the manuscript. MKS participation in laboratory analysis and assistance in drafting the manuscript. MC performed the statistical analysis, participated in drafting the manuscript. MW participation in conceiving and designing the study, assistance in material and data collection. JK participation in acquisition of funding, assistance in conceiving and designing the study, assistance in drafting the manuscript. All authors read and approved the final manuscript.

\section{Acknowledgments}

The work was supported by a grant from the National Science Centre in years 2010-2013 as a research project No. N N308 131638. The authors thank Barbara Chojnacka, Alicja Grzechnik, Teresa Zygmanowska and Beata Kowalkowska for excellent technical assistance.

\section{Author details}

'Laboratory of Veterinary Epidemiology and Economics, Faculty of Veterinary Medicine, Warsaw University of Life Sciences, Nowoursynowska159c, 02-776 Warsaw, Poland. ${ }^{2}$ Department of Preclinical Sciences, Faculty of Veterinary Medicine, Warsaw University of Life Sciences, Ciszewskiego 8, 02-786 Warsaw, Poland. ${ }^{3}$ Voivodeship Veterinary Inspectorate in Krosno, ks. Piotra

Ściegiennego 6 A, 38-400 Krosno, Poland. 
Received: 15 November 2014 Accepted: 13 May 2015

Published online: 22 May 2015

\section{References}

1. Carman MG, Hodges RT. Distribution of Rhodococcus equi in animals, birds and from the environment. N Z Vet J. 1987;35(7):114-5.

2. Takai S, Syakalima M, Yasuda J, Sasaki Y, Tsutsumi H, Miyagawa E, et al. Isolation of Rhodococcus equi from the feces of indigenous animals and soil from the Lower Zambezi National Park and Lochinvar National Park, Zambia. J Vet Med Sci. 2004;66(6):743-6.

3. Takai S, Tharavichitkul P, Takarn P, Khantawa B, Tamura M, Tsukamoto A, et al. Molecular epidemiology of Rhodococcus equi of intermediate virulence isolated from patients with and without acquired immune deficiency syndrome in Chiang Mai, Thailand. J infect dis. 2003;188(11):1717-23.

4. Takai S, Tharavichitkul P, Sasaki C, Onishi Y, Yamano S, Kakuda T, et al. Identification of virulence-associated antigens and plasmids in Rhodococcus equi from patients with acquired immune deficiency syndrome and prevalence of virulent R. equi in soil collected from domestic animal farms in Chiang Mai, Thailand. AmJrop Med Hyg. 2002;66(1):52-5.

5. Soedarmanto I, Zhicai W, Setyamahanani A, Lammler C. Pheno- and genotyping of Rhodococcus equi isolated from faeces of healthy horses and cattle. Res Vet Sci. 1998;64(3):181-5.

6. Giguere S, Cohen ND, Chaffin MK, Hines SA, Hondalus MK, Prescott JF, et al. Rhodococcus equi: clinical manifestations, virulence, and immunity. J Vet Med Sci. 2011;25(6):1221-30.

7. Komijn RE, Wisselink HJ, Rijsman VM, Stockhofe-Zurwieden N, Bakker D, van Zijderveld FG, et al. Granulomatous lesions in lymph nodes of slaughter pigs bacteriologically negative for Mycobacterium avium subsp. avium and positive for Rhodococcus equi. Vet Microbiol. 2007;120(3-4):352-7.

8. Shitaye JE, Parmova I, Matlova L, Dvorska L, Horvathova A, Vrbas V, et al. Mycobacterial and Rhodococcus equi infections in pigs in the Czech Republic between the years 1996 and 2004: the causal factors and distribution of infections in the tissues. Vet Med-Czech. 2006;51(11):497-511.

9. Poolkhet C, Chumsing S, Wajjwalku W, Minato C, Otsu Y, Takai S. Plasmid Profiles and Prevalence of Intermediately Virulent Rhodococcus equi from Pigs in Nakhonpathom Province, Thailand: Identification of a New Variant of the 70-kb Virulence Plasmid, Type 18. Veterinary med inter. 2010;2010:491624.

10. Dvorska L, Parmova I, Lavickova M, Bartl J, Vrbas V, Pavlik I. Isolation of Rhodococcus equi and atypical mycobacteria from lymph nodes of pigs and cattle in herds with the occurrence of tuberculoid gross changes in the Czech Republic over the period of 1996-1998. Vet Med-Czech. 1999;44(11):321-30.

11. Pate M, Ocepek M, Zdovc I, Minato C, Ohtsu Y, Matsuoka M, et al. Intermediately virulent Rhodococcus equi isolates from pigs in Slovenia: discovery of new plasmid types and assessment of genetic diversity by pulsed-field gel electrophoresis. Vet Med-Czech. 2009;54(3):111-7.

12. Ribeiro MG, Takai S, Guazzelli A, Lara GH, da Silva AV, Fernandes MC, et al. Virulence genes and plasmid profiles in Rhodococcus equi isolates from domestic pigs and wild boars (Sus scrofa) in Brazil. Res Vet Sci. 2011;91(3):478-81.

13. Lara GH, Ribeiro MG, Leite CQ, Paes AC, Guazzelli A, da Silva AV, et al. Occurrence of Mycobacterium spp. and other pathogens in lymph nodes of slaughtered swine and wild boars (Sus scrofa). Res Vet Sci. 2011;90(2):185-8.

14. Jeckel S, Holmes P, King S, Whatmore AM, Kirkwood I. Disseminated Rhodococcus equi infection in goats in the UK. The Veterinary record. 2011;169(2):56.

15. Flynn O, Quigley F, Costello E, O'Grady D, Gogarty A, Mc Guirk J, et al. Virulence-associated protein characterisation of Rhodococcus equi isolated from bovine lymph nodes. Vet Microbiol. 2001;78(3):221-8.

16. Sahraoui N, Muller B, Guetarni D, Boulahbal F, Yala D, Ouzrout R, et al. Molecular characterization of Mycobacterium bovis strains isolated from cattle slaughtered at two abattoirs in Algeria. BMC Vet Res. 2009:5:4.

17. Soedarmanto I, Oliveira R, Lammler C, Durrling H. Identification and epidemiological relationship of Rhodococcus equi isolated from cases of lymphadenitis in cattle. Int J Med Microbiol. 1997;286(4):457-67.

18. Takai S, Martens RJ, Julian A, Garcia Ribeiro M, Rodrigues de Farias M, Sasaki $Y$, et al. Virulence of Rhodococcus equi isolated from cats and dogs. J Clin Microbiol. 2003:41(9):4468-70

19. Makrai L, Kobayashi A, Matsuoka M, Sasaki Y, Kakuda T, Denes B, et al. Isolation and characterisation of Rhodococcus equi from submaxillary lymph nodes of wild boars (Sus scrofa). Vet Microbiol. 2008;131(3-4):318-23.
20. Sakai M, Ohno R, Higuchi C, Sudo M, Suzuki K, Sato H, et al. Isolation of Rhodococcus equi from wild boars (Sus scrofa) in Japan. J Wildl Dis. 2012;48(3):815-7.

21. Rzewuska M, Witkowski L, Cisek AA, Stefanska I, Chrobak D, Stefaniuk E, et al. Characterization of Rhodococcus equi isolates from submaxillary lymph nodes of wild boars (Sus scrofa), red deer (Cervus elaphus) and roe deer (Capreolus capreolus). Vet Microbiol. 2014;172(1-2):272-8.

22. de Vargas AC, Monego F, Gressler LT, de Avila BS, Lazzari AM, da Costa MM, et al. Bronchopneumonia in wild boar (Sus scrofa) caused by Rhodococcus equi carrying the VapB type 8 plasmid. BMC research notes. 2013;6:111.

23. Buergelt CD, Layton AW, Ginn PE, Taylor M, King JM, Habecker PL, et al. The pathology of spontaneous paratuberculosis in the North American bison (Bison bison). Vet Pathol. 2000;37(5):428-38.

24. Yamshchikov AV, Schuetz A, Lyon GM. Rhodococcus equi infection. Lancet Infect Dis. 2010;10(5):350-9.

25. Weinstock DM, Brown AE. Rhodococcus equi: an emerging pathogen. Clin Infect Dis. 2002;34(10):1379-85.

26. Ocampo-Sosa AA, Lewis DA, Navas J, Quigley F, Callejo R, Scortti M, et al. Molecular epidemiology of Rhodococcus equi based on traA, vapA, and vapB virulence plasmid markers. J Infect Dis. 2007;196(5):763-9.

27. Vazquez-Boland JA, Giguere S, Hapeshi A, MacArthur I, Anastasi E, Valero-Rello A. Rhodococcus equi: the many facets of a pathogenic actinomycete. Vet Microbiol. 2013;167(1-2):9-33.

28. Krajewska M, Lipiec M, Zabost A, Augustynowicz-Kopec E, Szulowski K: Bovine Tuberculosis in a Wild Boar (Sus scrofa) in Poland. J wildl dis 2014;50(4):1001-2.

29. Rzewuska M, Stefanska I, Osinska B, Kizerwetter-Swida M, Chrobak D, Kaba J, et al. Phenotypic characteristics and virulence genotypes of Trueperella (Arcanobacterium) pyogenes strains isolated from European bison (Bison bonasus). Vet Microbiol. 2012;160(1-2):69-76.

30. Morton AC, Begg AP, Anderson GA, Takai S, Lammler C, Browning GF. Epidemiology of Rhodococcus equi strains on Thoroughbred horse farms. Appl Environ Microbiol. 2001;67(5):2167-75.

31. Son WG, Lee DS, Yamatoda N, Hatori F, Shimizu N, Kakuda T, et al. Molecular typing of VapA-positive Rhodococcus equi isolates from Jeju native horses, Korea. J Vet Med Sci. 2006;68(3):249-53.

32. Venner M, Meyer-Hamme B, Verspohl J, Hatori F, Shimizu N, Sasaki Y, et al. Genotypic characterization of VapA positive Rhodococcus equi in foals with pulmonary affection and their soil environment on a warmblood horse breeding farm in Germany. Res Vet Sci. 2007:83(3):311-7.

33. Cohen ND, Smith KE, Ficht TA, Takai S, Libal MC, West BR, et al. Epidemiologic study of results of pulsed-field gel electrophoresis of isolates of Rhodococcus equi obtained from horses and horse farms. Am J Vet Res. 2003;64(2):153-61.

34. Bolton T, Kuskie K, Halbert N, Chaffin K, Healy M, Lawhon S, et al. Detection of strain variation in isolates of Rhodococcus equi from an affected foal using repetitive sequence-based polymerase chain reaction. J Vet Diagn Invest. 2010;22(4):611-5

35. Budny M, Panek M, Bresinski W, Kamieniarz B, Maka H. Sytuacja zwierząt łownych w Polsce - sezon łowiecki 2009/2010. In: Biuletyn Stacji Badawcze PZŁ w Czempiniu nr 7. Czempiń; 2010.

36. Thrusfield MV. Veterinary Epidemiology. 3rd ed. Wiley-Blackwell; 2007.

37. Tenover FC, Arbeit RD, Goering RV, Mickelsen PA, Murray BE, Persing DH, et al. Interpreting chromosomal DNA restriction patterns produced by pulsed-field Gel-electrophoresis - criteria for bacterial strain typing. J Clin Microbiol. 1995;33(9):2233-9.

\section{Submit your next manuscript to BioMed Central and take full advantage of:}

- Convenient online submission

- Thorough peer review

- No space constraints or color figure charges

- Immediate publication on acceptance

- Inclusion in PubMed, CAS, Scopus and Google Scholar

- Research which is freely available for redistribution 